\title{
Aircraft Trajectory Design Based on Reducing the Combined Effects of Carbon-Dioxide, Oxides of Nitrogen and Contrails
}

\author{
Banavar Sridhar ${ }^{1}$ and Neil Y. Chen ${ }^{2}$ \\ NASA Ames Research Center, Moffett Field, CA, 94035 \\ and \\ Hok K. $\mathrm{Ng}^{3}$ \\ University of California, Santa Cruz, Moffett Field, CA, 94035
}

\begin{abstract}
Aircraft operations need to meet the combined requirements of safety, efficiency, capacity and reduced environmental impact. Aircraft routes can be made efficient by flying wind optimal routes. However, the desire to reduce the impact of aviation emissions and contrails may result in trajectories, which deviate from wind optimal trajectories leading to extra fuel use. The lifetime associated with different emissions and contrails varies from a few hours to several hundred years. The impact of certain gases depends on the amount and location of the emission, and the decision-making horizon, in years, when the impact is estimated. The Absolute Global Temperature Potential (AGTP) is used as a metric to measure the combined effects of emissions and contrails. This paper extends earlier work by the authors to include the effect of oxides of nitrogen in the development of aircraft trajectories to reduce the combined effects of carbon dioxide, oxides of nitrogen $\left(\mathrm{NO}_{\mathrm{x}}\right)$ and contrails. The methodology is applied to air traffic in the continental US. The paper shows the trade-offs between reducing emissions and the cost of extra fuel using a fuel sensitivity index, defined as the reduction in AGTP per $\mathrm{kg}$ of fuel. The paper shows the performance of the optimization strategy for decision intervals of 10, 25 and 100 years. Based on the simplified models, the inclusion of $\mathrm{NO}_{\mathrm{x}}$ emissions has a slight influence on the minimal climate impact trajectories when the decision horizons are around 25 years.
\end{abstract}

\section{Introduction}

A VIATION operations affect the environment through the release of carbon dioxide $\left(\mathrm{CO}_{2}\right)$, water vapor, and oxides of nitrogen $\left(\mathrm{NO}_{\mathrm{X}}\right)$ and by the formation of contrails. Contrails are clouds that are visible trails of water vapor made by the exhaust of aircraft engines ${ }^{1}$. The climate impact of aviation is expressed in terms of "radiative forcing" (RF), which is a perturbation to the balance between incoming solar radiation and outgoing infrared radiation at the top of the troposphere. The amount of outgoing infrared radiation depends on the concentration of atmospheric greenhouse gases. Aviation contributes approximately $2 \%$ of all anthropogenic $\mathrm{CO}_{2}$ emissions. However, the latest estimates indicate that contrails caused by aircraft may be causing more climate warming today than all the residual $\mathrm{CO}_{2}$ emitted by aircraft ${ }^{2}$. The lifetime associated with different emissions and contrails varies from a few hours to several hundred years. The impact of certain gases depends on the amount and location of the emission, and the decision-making horizon, $\mathrm{H}$ in years, when the impact is estimated. These variations make it necessary to develop a common metric to quantify the impact of various gases. Several climate metrics that are dependent on the RF of the emissions and contrails have been developed to assess the impact. Using linear climate response models, the Absolute Global Temperature Potential (AGTP) measures the mean surface temperature change due to different aircraft emissions and persistent contrail formations ${ }^{3}$.

\footnotetext{
${ }^{1}$ Senior Scientist, Air Transportation Systems, Aviation Systems Division, MS 210-10, Fellow.

${ }^{2}$ Research Aerospace Engineer, Systems Modeling and Optimization Branch, MS 210-8, Senior member.

${ }^{3}$ Research Scientist, U.C. Santa Cruz, MS 210-8, Member
} 
Several methods have been proposed to reduce contrails by flying the aircraft around regions susceptible to contrail formation. Mannestein ${ }^{4}$ proposed a strategy to reduce the contrail formation by only small changes to individual flight altitude. Williams ${ }^{5}$ proposed strategies for contrail reduction by restricting aircraft cruise altitudes. These restrictions generally imply more fuel burn, thus more emissions, and add congestion to the already crowded airspace at lower altitudes. An energy efficient contrail reducing strategy has been developed by the authors ${ }^{6}$.

The objective of this paper is to develop methods to limit the impact of aviation on climate by adding the impact of $\mathrm{NO}_{\mathrm{X}}$ emissions to the efficient contrail reducing strategies. The simulation of $\mathrm{NO}_{\mathrm{X}}$ and the computation of the resulting climate impact are complicated by the indirect effect of $\mathrm{NO}_{\mathrm{X}}$ emissions. $\mathrm{NO}_{\mathrm{X}}$ increases the amount of ozone in the atmosphere while decreasing the amount of methane in the atmosphere. The amount of ozone produced depends on the lifetime of $\mathrm{NO}_{\mathrm{X}}$, which varies from days to weeks in the upper troposphere. The $\mathrm{RF}$ associated with $\mathrm{NO}_{\mathrm{X}}$ is made up of short-lived positive RF due to ozone and a negative RF due to methane and methane-induced reduction of ozone. However, the combined effect results in a net $\mathrm{RF}$ due to $\mathrm{NO}_{\mathrm{X}}{ }^{7}$. The effect depends strongly on the altitude and location of the emissions. This paper includes $\mathrm{NO}_{\mathrm{X}}$ in the climate metric, describes the climate impact reduction approach and describes the behavior of AGTP as a function of emissions, contrails and the decision interval. The optimization results from this research can be used as inputs to global climate modeling tools like the FAA's Aviation environmental Portfolio Management Tool for Impacts ${ }^{8}$.

The remainder of the paper is organized as follows. Section II provides a brief review of aircraft emissions. Section III provides the descriptions of the linear climate models used in this paper. Next, Section IV describes the climate reduction strategies. Section V shows the simulations results based on the models. Finally, a summary and conclusions are presented in Section VI.

\section{Aircraft Emissions}

Water vapor and $\mathrm{CO}_{2}$ are two greenhouse gases produced by aviation. The RF associated with water vapor is very small and is neglected in this analysis. The aircraft engine produces $3.155 \mathrm{~kg}$ of $\mathrm{CO}_{2}$ while burning a $\mathrm{kg}$ of aviation fuel. The amount of $\mathrm{CO}_{2}$ produced is independent of the location of the aircraft. $\mathrm{CO}_{2}$ has a long lifetime and is globally well mixed, which results in a RF value insensitive to the location of the emissions.

Although air traffic is the major source of $\mathrm{NO}_{\mathrm{X}}$ in the atmosphere, modeling the impact of aviation $\mathrm{NO}_{\mathrm{X}}$ is complicated due to contributions from other sources such as lightning, downward transport of $\mathrm{NO}_{\mathrm{X}}$ from stratosphere and convected uplift of $\mathrm{NO}_{\mathrm{X}}$ from polluted regions near the ground. The amount of $\mathrm{NO}_{\mathrm{X}}, \mathrm{E}_{\mathrm{NOX}}$, produced by the engine is small compared to the amount of $\mathrm{CO}_{2}$ and varies with altitude. It can be expressed as $\mathrm{E}_{\mathrm{NOX}}=\mathrm{EINO}_{\mathrm{X}}{ }^{*} \mathrm{FB}$, where $\mathrm{EINO}_{\mathrm{X}}$ is the Emission Index of NOx, $\mathrm{E}_{\mathrm{NOX}}$ is in grams and fuel burned, $\mathrm{FB}$, is in $\mathrm{kg}$. $E N_{\mathrm{X}}$ takes into account the dependency of the amount of $\mathrm{NO}_{\mathrm{X}}$ produced as a function of altitude and the variation is shown in Figure 1. The amount of $\mathrm{NO}_{\mathrm{X}}$ produced varies from $0.87-0.78$ grams $/ \mathrm{kg}$ of fuel for the altitude range of $30,000-40,000$ feet.

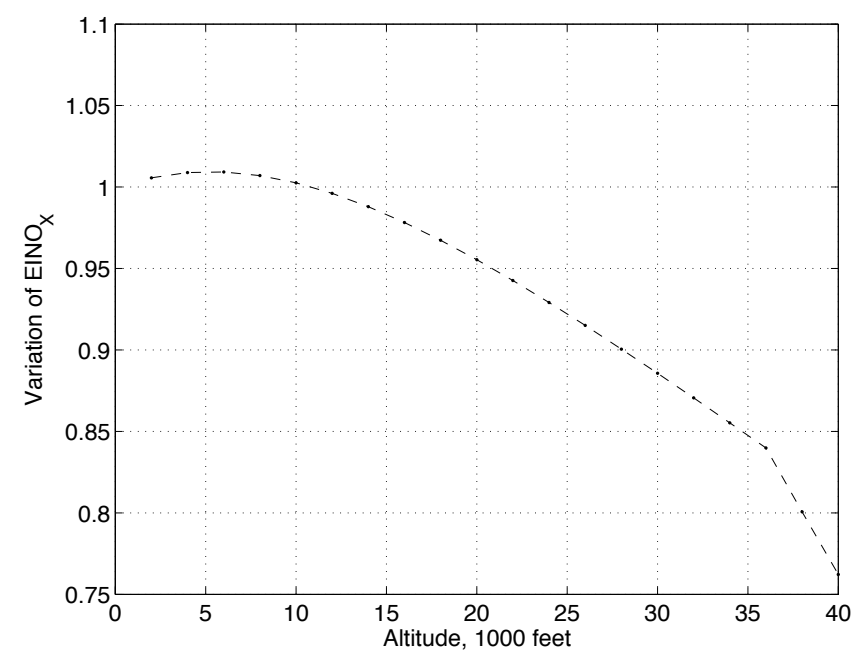

Figure 1. Variation of EINO $_{\mathrm{X}}$ with altitude for the standard atmosphere.

NOx is a short-life chemically reactive gas. It affects the radiation balance indirectly by changing the distributions of ozone $\left(\mathrm{O}_{3}\right)$, methane $\left(\mathrm{CH}_{4}\right)$ and hydrofluorocarbons (HFC) in the atmosphere. The atmospheric 
effect of NOx can be divided into two parts: (a) an increase in regional tropospheric $\mathrm{O}_{3}$ and (b) a small decrease in the amount of methane. The net RF from NOx is the difference between the heating effect of increasing $\mathrm{O}_{3}$ and the cooling effect of decreasing amount of methane. The reduction of methane has a secondary effect by reducing the tropospheric ozone and a long-term reduction in water vapor in the stratosphere from reduced oxidation of methane. The net effect of all these reactions is considered to be a net positive $\mathrm{RF}$ due to $\mathrm{NO}_{\mathrm{X}}$. An accurate estimation of the $\mathrm{RF}$ due to $\mathrm{NO}_{\mathrm{X}}$ requires global chemistry transport models and depends on the background emissions from other sources. However, it has been shown that linear models are a good approximation to estimate the atmospheric impact of changes to baseline emission profile without resorting to complicated transport models ${ }^{9}$.

\section{Linear Climate Models}

This section models the climate response to aircraft $\mathrm{CO}_{2}$ and NOx emissions and contrails as outputs from a series of linear dynamic systems. The climate response models for aircraft $\mathrm{CO}_{2}$ emission and contrails were developed in a previous study. ${ }^{10}$ The climate impact of aircraft $\mathrm{NO}_{\mathrm{X}}$ emission is modeled similarly and presented in this study. Section IIA introduces AGTP as the climate metric used in this study for assessing aviation-induced global warming. Section IIB IIC, and IID models AGTP due to $\mathrm{CO}_{2}$ emission, $\mathrm{NO}_{\mathrm{X}}$ emission and contrails, respectively.

\section{A. Absolute Global Temperature Change Potential}

Absolute Global Temperature Change Potential (AGTP) ${ }^{11}$ is a climate assessment metric that adapts a linear system for modeling the global temperature response to aviation emissions and contrails. It is defined as a convolution integral from $\mathrm{t}_{0}=0$ to $\mathrm{t}=\mathrm{H}$, and has the following representation,

$$
A G T P(H)=\int_{0}^{H} R(H-\zeta) \Delta F(\zeta) d \zeta
$$

where $R(H-\zeta)$ is the impulse response function for the surface temperature change at time $H$ due to a change in radiative forcing $\Delta F(\zeta)$ applied at $\zeta$. Note that temperature change $\Delta T\left(t, t_{0}\right)$ on the Earth surface is equivalent to the $\operatorname{AGTP}(H)$ when simplified climate model is chosen. Two versions of AGTP are available in the literature. The pulse AGTP measures the change in the global temperature at a particular time, $t$, in the future due to an instantaneous input at $t_{0}$. The sustained AGTP measures the global temperature change at time $t$ due to a constant input applied for a period between $t_{0}$ and $t$. The units of AGTP are in degrees Kelvin (K).

The pulse AGTP is employed in this study for translating aviation induced $\mathrm{CO}_{2}$ and $\mathrm{NO}_{\mathrm{X}}$ emissions and persistent contrails into total effect on global warming. The formulations for AGTP due to $\mathrm{CO}_{2}$ and $\mathrm{NO}_{\mathrm{x}}$ emissions and contrails are provided in the following subsections.

\section{B. Pulse AGTP for $\mathrm{CO}_{2}$ emission}

The impact of $\mathrm{CO}_{2}$ on climate is better understood than the impact of all other greenhouse gases and contrails. The carbon cycle models describe the changes to the $\mathrm{CO}_{2}$ concentration due to the transport and absorption of $\mathrm{CO}_{2}$ by the land mass and various ocean layers. The change in $\mathrm{RF}$ for $\mathrm{CO}_{2}$ emissions, $\Delta F^{\mathrm{CO}_{2}}$, is made of a steady-state component and three exponentially decaying components with a specific forcing, $A^{\mathrm{CO}_{2}}=1.82 \times 10^{-15} \mathrm{Wm}^{-2} / \mathrm{kg} \mathrm{of} \mathrm{CO}_{2}$, a value taken from past studies ${ }^{12}$. The temperature response/energy balance to RF, $R(H-\zeta)$ can be modeled using either a first order linear mode ${ }^{13}$ or a second order linear mode ${ }^{14}$. The time constants in the two-box ocean model correspond to the dynamics associated with the surface layers of the ocean and the thermal inertia associated with the deep ocean. The pulse AGTP for $1 \mathrm{~kg} \mathrm{CO}_{2}$ emission for a time horizon $H$ can then be found based on Eq. (1) by applying a second order model for the impulse response function, $R(t)=\sum_{j=1}^{2} \frac{c_{j}}{d_{j}} e^{-t / d_{j}}$, and is given by

$$
A G T P^{C O_{2}}(H)=A^{C O_{2}} \sum_{j=1}^{2}\left[a_{0} c_{j}\left(1-e^{-H / d_{j}}\right)+\sum_{i=1}^{3} \frac{a_{i} \alpha_{i} c_{j}}{\alpha_{i}-d_{j}}\left(e^{-H / \alpha_{i}}-e^{-H / d_{j}}\right)\right] .
$$

where the parameters $a_{i}, \alpha_{i}, c_{j}$ and $d_{j}$ are taken from the literature ${ }^{3}$. 


\section{AGTP for $\mathrm{NO}_{\mathrm{x}}$ emission}

The climate impact of aircraft $\mathrm{NO}_{\mathrm{x}}$ emissions in terms of AGTP is provided in this section. This study assumes that the RF associated with $\mathrm{NO}_{\mathrm{x}}$ is constant and independent of emission location and time. The model can be improved by making the RF values depend on the emission location such as latitude and altitude, and time of the year $^{15}$.

The $\mathrm{NO}_{\mathrm{x}}$ emission lead to changes ${ }^{7}$ in ozone, $\mathrm{O}_{3}$, and methane, $\mathrm{CH}_{4}$. The radiative forcing is assumed to be a result of a one-year step emission in year 1 followed by an exponential decay of the resulting forcing from the endof-year 1 value. The sustained AGTP for $1 \mathrm{~kg} \mathrm{NO}$ emission for a year with a time horizon $H$ is given by

$$
\operatorname{AGTP}^{N O_{x}}(H)=A G T P_{O_{3}}^{S}(H)+A G T P_{C_{4}}(H)+A_{G T P_{O_{3}}^{P M}}(H)
$$

where the AGTP for short-lived $\mathrm{O}_{3}$ perturbation:

$$
A G T P_{O_{3}}^{S}(H)=\Delta F_{O_{3}}^{S, S S}\left(1-\exp \left(\frac{-1}{\alpha_{s}}\right)\right) \sum_{j=1}^{2}\left\{\frac{c_{j} \alpha_{s}}{\alpha_{s}-d_{j}}\left[\exp \left(\frac{1-H}{\alpha_{s}}\right)-\exp \left(\frac{1-H}{d_{j}}\right)\right]\right\} \text { for } H \geq 1
$$

The AGTP for methane perturbation:

$$
\operatorname{AGTP}_{C_{4}}(H)=\Delta F_{C H_{4}}^{S S}\left(1-\exp \left(\frac{-1}{\alpha_{P M}}\right)\right) \sum_{j=1}^{2}\left\{\frac{c_{j} \alpha_{P M}}{\alpha_{P M}-d_{j}}\left[\exp \left(\frac{1-H}{\alpha_{P M}}\right)-\exp \left(\frac{1-H}{d_{j}}\right)\right]\right\} \text { for } H \geq 1
$$

The AGTP for methane-induced $\mathrm{O}_{3}$ perturbation:

$$
A G T P_{O_{3}}^{P M}(H)=\Delta F_{O_{3}}^{P M}, S S\left(1-\exp \left(\frac{-1}{\alpha_{P M}}\right)\right) \sum_{j=1}^{2}\left\{\frac{c_{j} \alpha_{P M}}{\alpha_{P M}-d_{j}}\left[\exp \left(\frac{1-H}{\alpha_{P M}}\right)-\exp \left(\frac{1-H}{d_{j}}\right)\right]\right\}
$$

where the parameters $\alpha_{s}, \alpha_{P M}, \Delta F_{O_{3}}^{S, S S}, \Delta F_{O_{3}}^{P M}$ and $\Delta F_{C H_{4}}^{S S}$ are taken from the literature ${ }^{3}$. The AGTP values for $1 \mathrm{~kg}$ of $\mathrm{CO}_{2}$ emission and $1 \mathrm{~kg}$ of $\mathrm{NO}_{\mathrm{x}}$ emission are plotted in Fig. 2.

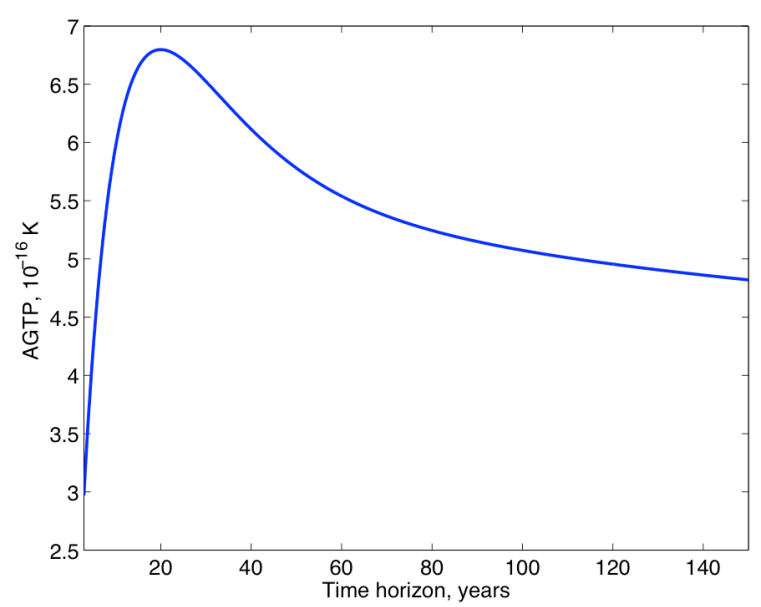

(a) $\mathrm{CO}_{2}$

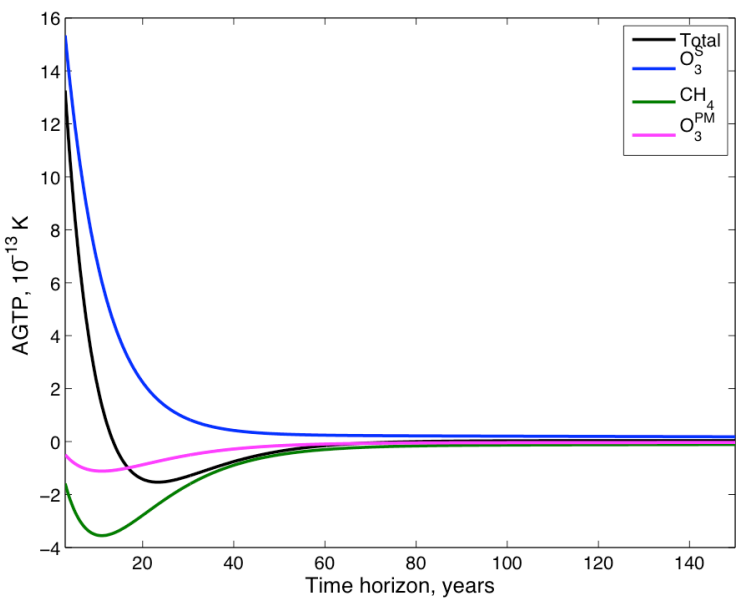

(b) $\mathrm{NO}_{X}$

Figure 2. AGTP values for $\mathrm{CO}_{2}$ emission and $\mathrm{NO}_{\mathrm{x}}$ emission. 


\section{Pulse AGTP for Persistent Contrails}

The surface temperature response for contrails is modeled similarly. An impulse function best characterizes contrails radiative forcing since contrails are short-lived; usually last for several hours, in the atmosphere. The pulse AGTP for contrails formation is simply taken as the impulse response. For a unit of contrails induced radiative forcing, $\delta$, the pulse AGTP is represented by

$$
A G T P^{\text {Contrails }}(H)=\int_{0}^{H} R(H-\zeta) \delta(\zeta-0) d \zeta=R(H)
$$

Equation (7) computes surface temperature change due to a unit of energy induced to the atmosphere by contrails. Note that $A G T P^{\text {Contrails }}(H)$ is equal to the impulse response function, $R(H)$. The net radiative forcing for contrails includes the long wave $R F_{L W}$ and the short wave $R F_{S W}$ radiative forcing and is defined as $R F_{\text {nets }}=R F_{L W}+R F_{S W}$. It is measured in terms of unit of power (Watts) per unit area of contrails $\left(\mathrm{m}^{2}\right)$. Typical values for $R F_{\text {nets }}$ have a range between $10 \mathrm{Wm}^{-2}$ and $30 \mathrm{Wm}^{-2}$ taken from Meerkötter ${ }^{16}$ and Haywood ${ }^{17}$. Due to the nature of contrail formation, it is argued that it is better to represent contrail radiative forcing in terms of unit distance flown by the aircraft (watts $/ \mathrm{km}$ ). The amount of energy, $E F$, induced to the atmosphere for a unit length of contrail over its lifetime is defined as ${ }^{18}$

$$
E F=\int_{\text {lifetime }} R F_{\text {nets }}(\zeta) W_{c}(\zeta) d \zeta
$$

where $W_{c}$ is contrail width (m). Suppose $R F_{\text {nets }}=10 \mathrm{Wm}^{-2}$, contrail width $W=1000 \mathrm{~m}$ and contrail lifetime is $10000 \mathrm{~s}$, the energy $E F$ for a $\mathrm{km}$ contrail equals 100 Gigajoules (GJ). The global surface temperature change, $\operatorname{AGTP}^{\text {Contrails }}(H)$, is then computed by multiplying the impulse response function shown in Eq. (7) by the total energy in Eq. (8) after it is normalized by the surface area of the Earth and total seconds in a year.

\section{Climate Impact Reduction Methodology}

Absolute Global Temperature Potential (AGTP) provides a way to express the combined environmental cost of $\mathrm{CO}_{2}, \mathrm{NO}_{\mathrm{X}}$ and contrails as a function of the fuel cost. Assuming, initially, that the RF due to contrails and $\mathrm{NO}_{\mathrm{X}}$ is independent of altitude and location, the near surface temperature change can be approximated as

$$
\Delta T=\Delta T_{\mathrm{CO}_{2}}+\Delta T_{\mathrm{NO}_{x}}+\Delta T_{\text {Contrail }}
$$

where $\Delta T_{\mathrm{CO}_{2}}$ is the contribution to AGTP from $\mathrm{CO}_{2}$ emissions and is equal to $\alpha$ times additional $\mathrm{CO}_{2}$ emissions in $\mathrm{kg}, \Delta T_{N O_{X}}$ is the contribution to AGTP from $\mathrm{NO}_{\mathrm{X}}$ emissions and is equal to $\gamma$ times additional $\mathrm{NO}_{\mathrm{X}}$ emissions in $\mathrm{kg}$ and $\Delta T_{\text {Contrail }}$ is the contribution to AGTP from contrails and is equal to $\beta$ times contrail formation in $\mathrm{km}$. The values of $\alpha, \gamma$ and $\beta$ depend on the linear models for $\mathrm{RF}$, the specific forcing because of $\mathrm{CO}_{2}$ and $\mathrm{NO}_{\mathrm{X}}$, energy balance model and the duration of the climate effect horizon ${ }^{4}$. The units for $\Delta T, \alpha, \gamma$ and $\beta$ are degrees $\mathrm{K}, \mathrm{K} / \mathrm{kg}, \mathrm{K} / \mathrm{kg}$ and $\mathrm{K} / \mathrm{km}$. The coefficient $\alpha, \gamma$ and $\beta$ for different time horizons are shown in Table 1 .

Table 1. AGTP coefficients due to $\mathrm{CO}_{2}, \mathrm{NO}_{\mathrm{X}}$, and contrails at different time horizons.

\begin{tabular}{|l|c|c|c|c|c|}
\hline H (years) & 5 & 10 & 25 & 100 & 500 \\
\hline$\alpha(\mathrm{K} / \mathrm{kg})$ & $4.2 \mathrm{e}-16$ & $6.0 \mathrm{e}-16$ & $6.73 \mathrm{e}-16$ & $5.13 \mathrm{e}-16$ & $4.3 \mathrm{e}-16$ \\
\hline$\gamma(\mathrm{K} / \mathrm{kg})$ & $8.8 \mathrm{e}-13$ & $2.2 \mathrm{e}-13$ & $-1.5 \mathrm{e}-13$ & $2.8 \mathrm{e}-15$ & $1.4 \mathrm{e}-15$ \\
\hline$\beta(\mathrm{K} / \mathrm{km})$ & $2.6 \mathrm{e}-13$ & $1.5 \mathrm{e}-13$ & $3.0 \mathrm{e}-14$ & $5.1 \mathrm{e}-15$ & $1.9 \mathrm{e}-15$ \\
\hline
\end{tabular}

Many concepts have been developed to minimize $\Delta T$ due to $\mathrm{CO}_{2}$ and contrails by varying the three dimensional trajectories of the aircraft. A previous paper by the authors ${ }^{6}$ minimized $\Delta T$ ignoring the contributions of $\mathrm{NO}_{\mathrm{X}}$. This paper adds the effect of $\mathrm{NO}_{\mathrm{X}}$ and studies its effect on the minimization of $\Delta T$. The traffic and climate impact simulations over the continental US are performed using the Future Air Traffic Management Concepts Evaluation 

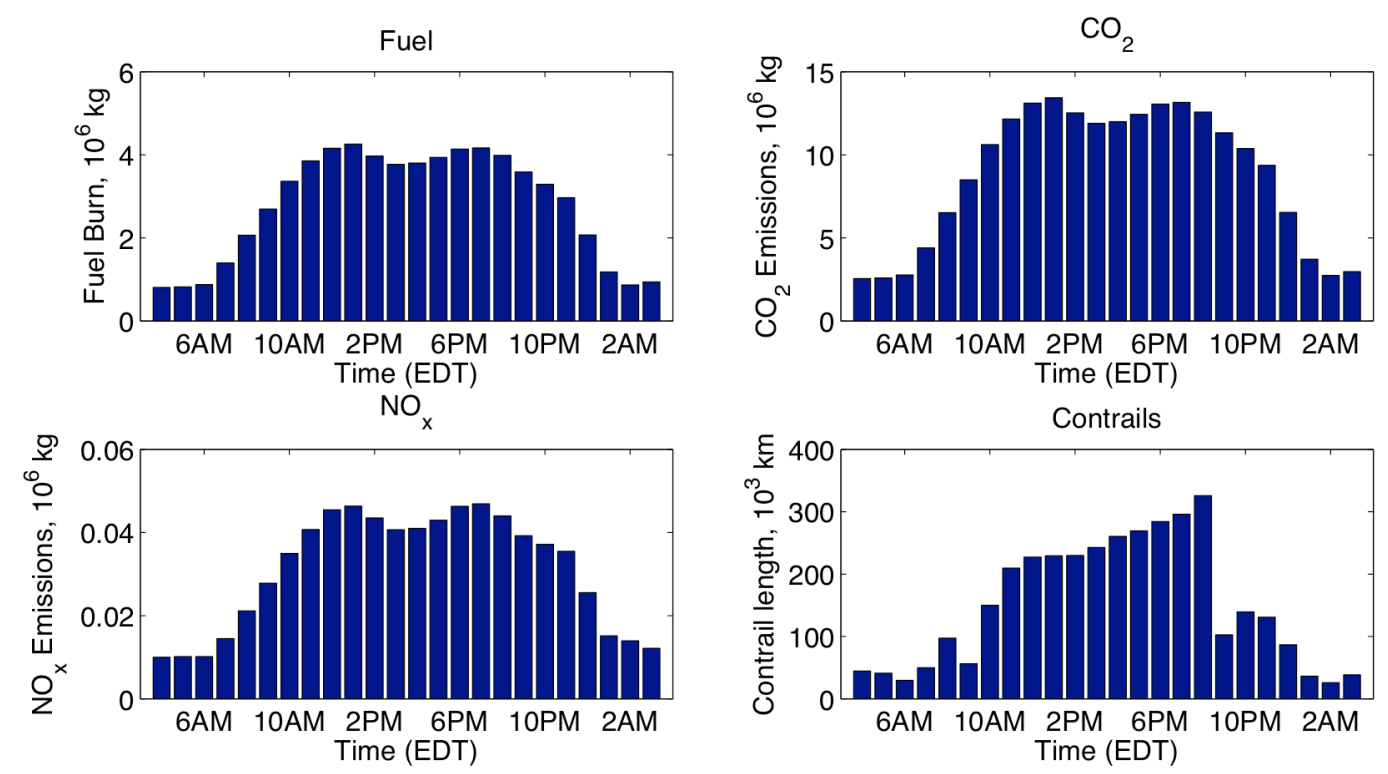

Figure 3. Fuel consumption, $\mathrm{CO}_{2}, \mathrm{NO}_{\mathrm{X}}$ and contrails produced by aircraft in US during a day.

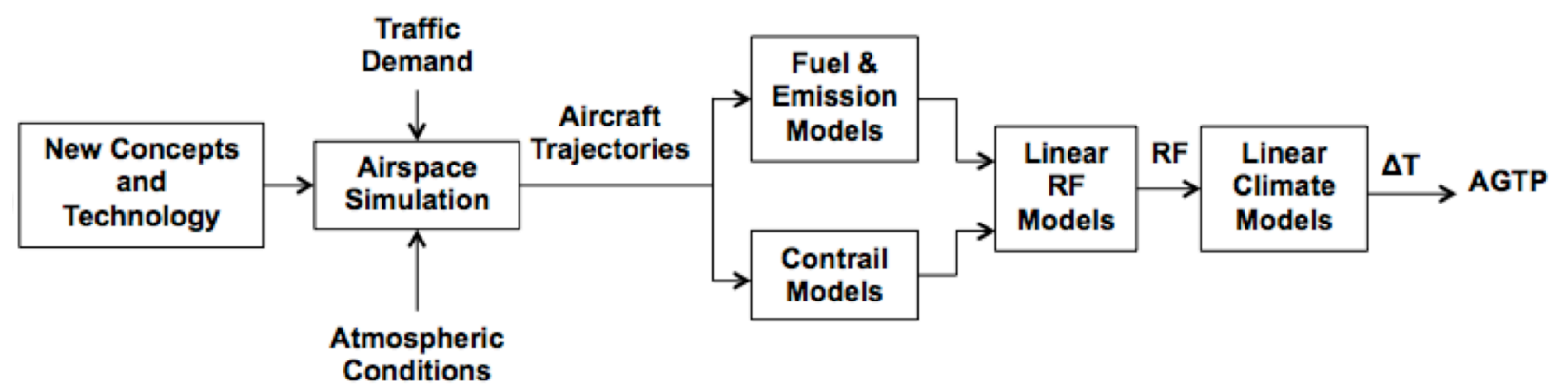

Figure 4. Computation of AGTP.

Tool $(\mathrm{FACET})^{19}$. Figure 3 shows the fuel consumption, $\mathrm{CO}_{2}, \mathrm{NO}_{\mathrm{X}}$ and contrails generated by aircraft flying in the continental United States on a typical day (April 12, 2010). The steps involved in the computation of AGTP are shown in Fig. 4.

The climate impact reduction strategy uses the same approach as in Reference 20. The strategy is to minimize $\Delta \mathrm{T}$ instead of minimizing the contrail formation as in Reference 20 . The strategy divides the U.S. national airspace into twenty regions horizontally based on the twenty continental U.S. air traffic control centers, and ten levels vertically, from 26,000 feet to 44,000 feet with an increment of 2,000 feet. At each hour, the strategy looks at all aircraft cruising in a center at the same flight level, alters their cruise altitude by $-4,000,-2000,+2000$, or $+4,000$ feet, and selects the optimal cruise altitude that provides the minimal $\Delta T$. The strategy also computes the additional fuel burn needed for such a move, and uses a fuel-temperature sensitivity index, $\Delta T$ reduction per additional fuel burn, to determine the fuel-sensitivity of each move. For example, if moving all the aircraft at a center up 2,000 feet will burn $1,000 \mathrm{~kg}$ more fuel and reduce $\Delta T$ by $2 \times 10^{-10} \mathrm{~K}$, and if moving the aircraft down 2,000 will reduce $\Delta T$ by $3 \times 10^{-10} \mathrm{~K}$ but will burn $10,000 \mathrm{~kg}$ additional fuel, the strategy to minimize the climate impact will choose to move aircraft 2,000 feet lower to reduce $\Delta T$ by $3 \times 10^{-10} \mathrm{~K}$. However, if the strategy looks at the fuel-sensitivity index and will only move when the fuel-sensitivity index is greater than $10^{-10} \mathrm{~K} / 1000 \mathrm{~kg}$, the strategy will choose to move aircraft 2,000 feet higher. Even though the $\Delta T$ reduction is $10^{-10} \mathrm{~K}$ less, the additional fuel burn is 10 times less. Using different thresholds on the fuel-sensitivity index allows the strategy to tradeoff fuel burn with $\Delta T$. Note that the strategy is applied to each center at each hour independently. Also these altitude changes are subject to the cruise altitude limits of each aircraft. An additional constraint is added such that where an aircraft crosses a sector boundary and causes congestion, it will stay at the original cruise altitude. Additional conditions can be added to satisfy other operational procedures. 


\section{Results}

Using the steps indicated in Fig. 4, the data from a typical day (April 12, 2012) were analyzed to: (1) estimate the total AGTP changes due to $\mathrm{CO}_{2}, \mathrm{NO}_{\mathrm{X}}$ and contrails as a function of time horizon and (2) develop a climate impact reduction strategy. Figure 5 shows the results of the analysis to determine the impact of emissions and contrails as a function of time horizon. Fig. 5a shows the total AGTP and the AGTP changes due to $\mathrm{CO}_{2}, \mathrm{NO}_{\mathrm{X}}$ and contrails are shown in Fig. 5b. The total AGTP at the end of 10,25 and 100 years is $8.22 * 10^{\wedge}-7 \mathrm{~K}, 1.37^{*} 10^{\wedge}-7 \mathrm{~K}$ and $1.28 * 10^{\wedge}-7 \mathrm{~K}$ respectively. As indicated in the figure, contrails have more impact in terms of AGTP for shorter time horizons. The AGTP impact of $\mathrm{CO}_{2}$ is relatively steady at different time horizons. The AGTP impact of $\mathrm{NO}_{\mathrm{X}}$ is larger than $\mathrm{CO}_{2}$ but much less than contrails for a time horizon of 10 years. It is negative at a time horizon of 25 years, and is relatively small compared to $\mathrm{CO}_{2}$ for a time horizon of 100 years. These figures will change depending on the performance of the climate impact reduction strategy.

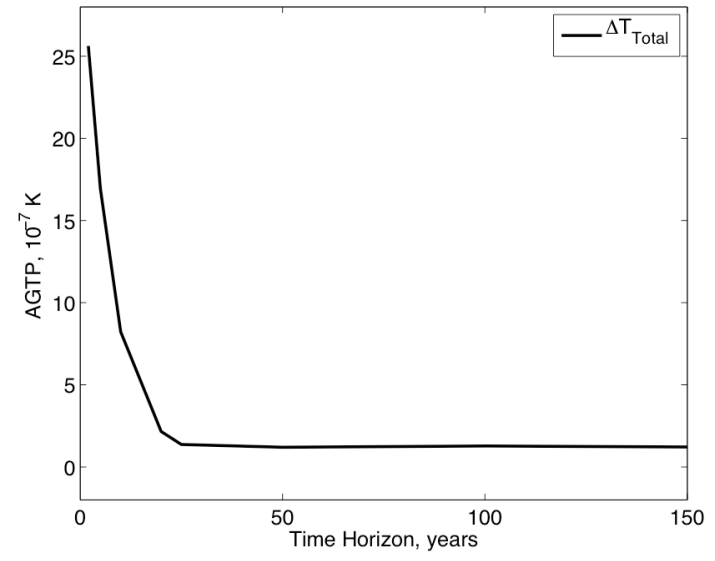

(a)

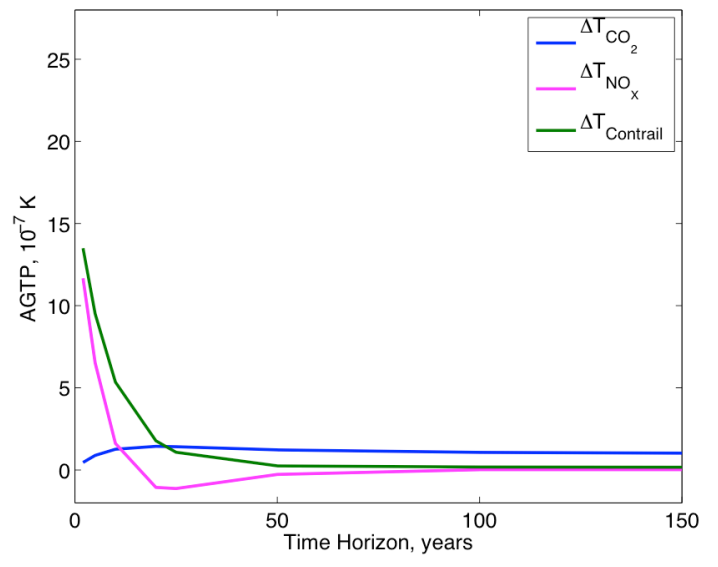

(b)

Figure 5. AGTP changes due to daily $\mathrm{CO}_{2}, \mathrm{NO}_{\mathrm{X}}$ and contrails caused by aircraft in US during a day.

Figure 6 summarizes the trade-off between reduction in AGTP and additional fuel consumption for a time horizon of 100 years when the aircraft altitudes are allowed to change in the range of $-4,000$ to +4000 feet for a $24-$ hour period on April 12, 2010. The RF value is set to $30 \mathrm{~mW} / \mathrm{m}^{2}$ for contrails. The strategy is applied while maintaining the baseline routing and enforcing the airspace capacity and aircraft maximum cruise speed constraint. The lower-right point of the black curve, indicated by X, in Fig 6a denotes the point of minimum climate impact by reducing the total AGTP by $9 \times 10^{-9} \mathrm{~K}$ while consuming $1.1 \times 10^{6} \mathrm{~kg}$ additional fuel burn. The plot in Fig. $6 \mathrm{a}$ shows that moving from maximum climate reduction point $(\mathrm{X})$ to baseline fuel usage point $(\mathrm{O})$ result in less AGTP reduction, less additional fuel burn and a more fuel-efficient strategy. Figure $6 \mathrm{~b}$ shows the contributions to AGTP from $\mathrm{CO}_{2}, \mathrm{NO}_{\mathrm{X}}$, and contrails. As indicated in the figure, for $\mathrm{H}=100$, the reduction in $\Delta T$ (black line) is mainly

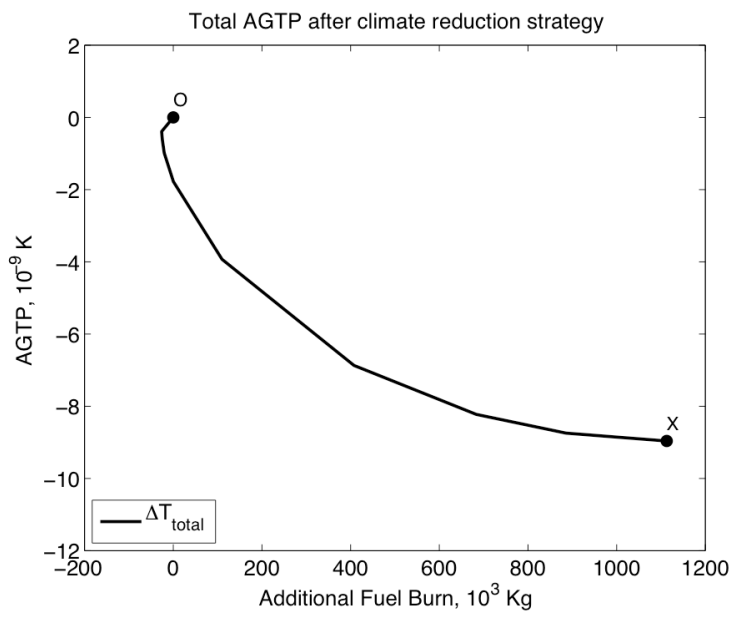

(a)

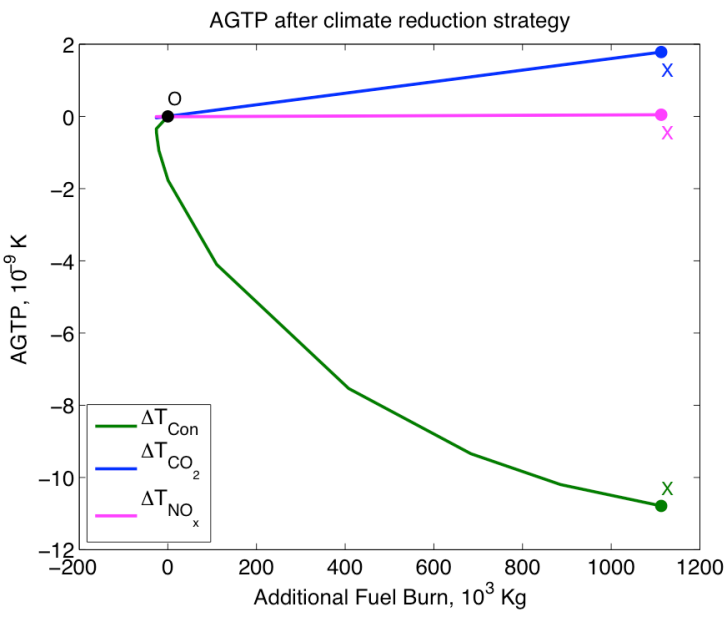

(b)

Figure 6. AGTP $(\mathrm{H}=100)$ reduction vs. additional fuel burn after climate reduction strategy on April 12,2010. 
driven by the reduction in $\Delta T_{\text {Contrail }}$ (green line). The additional fuel burn results in increasing contributions from $\Delta T_{\mathrm{CO}_{2}}$ (blue line) and a smaller amount of increase due to $\Delta T_{\mathrm{NO}_{X}}$ (megenta line). The changes to emissions and contrail length resulting from the climate impact reduction strategy are shown in Fig. 7.

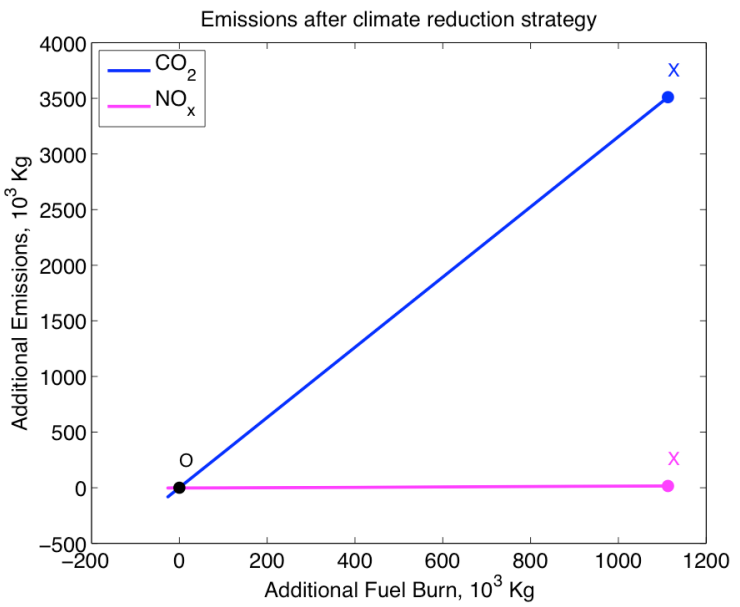

(a)

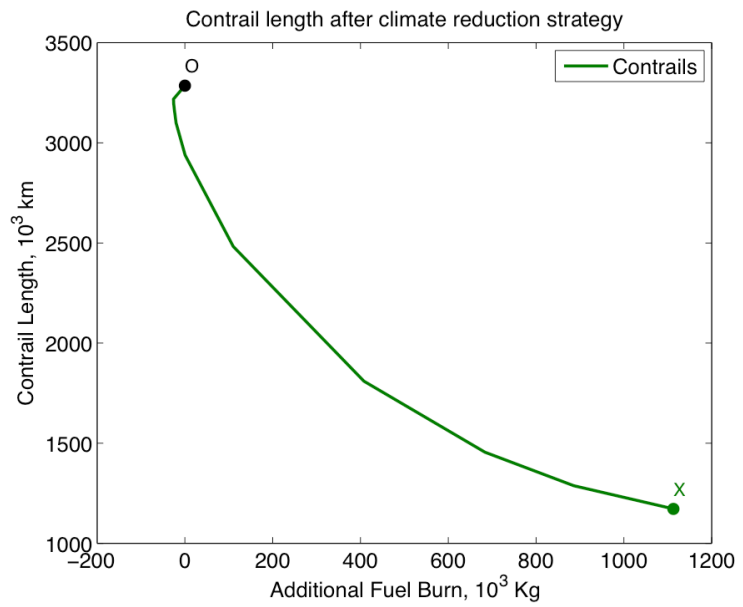

(b)

Figure 7. Changes in emissions and contrails versus additional fuel burn after climate reduction strategy on April 12, 2010.

The climate impact reduction strategy performs differently with different target time horizons. Similar to the climate impact reduction strategy for decision time horizon $\mathrm{H}=100$ years, shown in Fig. $6 \mathrm{a}$ and $6 \mathrm{~b}$, the total reduction in AGTP and AGTP contributions due to $\mathrm{CO}_{2}, \mathrm{NO}_{\mathrm{X}}$ and contrails after the implementation of climate impact strategy with decision time horizons $\mathrm{H}=25$ and 10 are shown in Fig $8 \mathrm{a}$ and $8 \mathrm{~b}$. As before the AGTP changes are shown as changes to the baseline operation, indicated by $\mathrm{O}$, in the rest of the figures. As shown in Fig 8a, for $\mathrm{H}=25$, the reduction in $\Delta T$ (black line) is mainly driven by the reduction in $\Delta T_{\text {contrail }}$ (green line) with additional reduction from $\Delta T_{N O_{X}}$ (megenta line). The total $\mathrm{NO}_{\mathrm{X}}$ emissions are increaing because of additional fuel burn, but the AGTP due to $\mathrm{NO}_{\mathrm{X}}$ is reducing because of the AGTP coefficient of $\mathrm{NO}_{\mathrm{X}}, \gamma$, is negative, as indicated in Fig. 2 and Table 1. $\Delta T_{\mathrm{CO}_{2}}$ (blue line) is linearly increasing with the additional fuel burn at a smaller rate than the decrease in $\Delta T_{\text {Contrail }}$. Figure $8 \mathrm{~b}$ shows the AGTP changes after the application of climate impact strategy with a decision horizon $\mathrm{H}=10$ years. Similar to Fig. 6a and $6 \mathrm{~b}$, total AGTP reduction, $\Delta T$ (black line), is mainly driven by the reduction in $\Delta T_{\text {Contrail }}$ (green line). The additional fuel burn results in increases in $\Delta T_{\mathrm{CO}_{2}}$ (blue line) and $\Delta T_{\mathrm{NO}_{X}}$, but the amount is relatively negligable compared to $\Delta T_{\text {Contrail }}$ for short time horizon ( $\mathrm{H}=10$ years). In summary, for

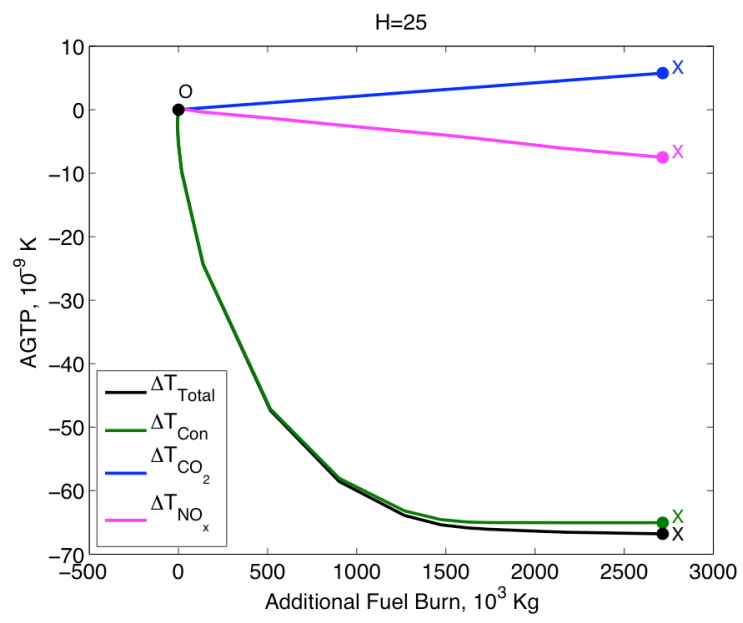

(a)

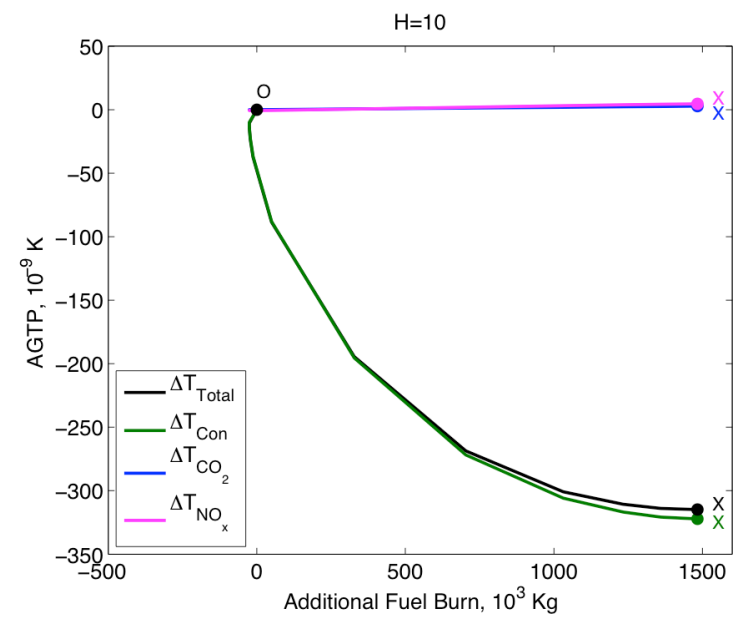

(b)

Figure 8. AGTP reduction $(\mathrm{H}=25,10)$ versus additional fuel burn after the climate reduction strategy for all flights on April 12, 2010. 
short decision time horizon ( $\mathrm{H}=10$ years), the climate impact strategy is mainly driven by finding the strategy to reduce contrail formation. For the decision time horizon when the AGTP coefficient of $\mathrm{NO}_{\mathrm{X}}, \gamma$, is negative $(\mathrm{H}=25$ years), the AGTP effect of $\Delta T_{\mathrm{CO}_{2}}$ would be reduced by $\Delta T_{\mathrm{NO}_{X}}$ and $\Delta T_{\text {Contrail }}$ becomes the dominant term. For longer decision time horizon ( $\mathrm{H}=100$ years), $\Delta T_{\mathrm{CO}_{2}}$ and $\Delta T_{N O_{X}}$ have more impact on the strategy.

To determine if considering $\mathrm{NO}_{\mathrm{X}}$ emissions would affect the climate impact reduction strategy, the same analysis was repeated without adding the AGTP due to $\mathrm{NO}_{\mathrm{X}}$ to the objective function. In other words, the strategy is now trying to minimize the $\Delta T$ defined as

$$
\Delta T=\Delta T_{\mathrm{CO}_{2}}+\Delta T_{\text {Contrail }}
$$

To compare the strategies with and without considering $\mathrm{NO}_{\mathrm{X}}$ emissions, the total AGTP reduction due to $\mathrm{CO}_{2}$ and contrails are shown in Fig 9. As shown in Fig. 9a and 9c, the climate impact reduction strategy makes no difference with or without considering the $\mathrm{NO}_{\mathrm{X}}$ emissions with decision time horizon at 10 years and 100 years. However, at a decision time horizon of 25 years, the strategies are slightly different. The differences in the behavior of $\mathrm{NO}_{\mathrm{x}}$ at different time horizons can be explained by recalling that the effect of $\mathrm{NO}_{\mathrm{X}}$ emissions on the environment is to increase the amount of ozone, decrease the amount of methane and a reduction in the amount of ozone due to the reduction in methane. The AGTP effect of $\mathrm{NO}_{\mathrm{X}}$ is due to the combined effect of these three chemical reactions of varying magnitudes and dynamics. As can be seen from Fig. $2 \mathrm{~b}$, the resulting AGTP due to $\mathrm{NO}_{\mathrm{X}}$ is a function of the time horizon, is positive at 10 years, slightly negative at 25 years and small, but positive, at 100 years. While considering $\mathrm{NO}_{\mathrm{X}}$ emissions, there will be more altitude moves available that could reduce total AGTP with additional fuel burn compared to a strategy that ignores the effect of $\mathrm{NO}_{\mathrm{X}}$ emissions. These results need to be confirmed by studying more days and in the presence more detailed contrail and $\mathrm{NO}_{\mathrm{X}}$ models.

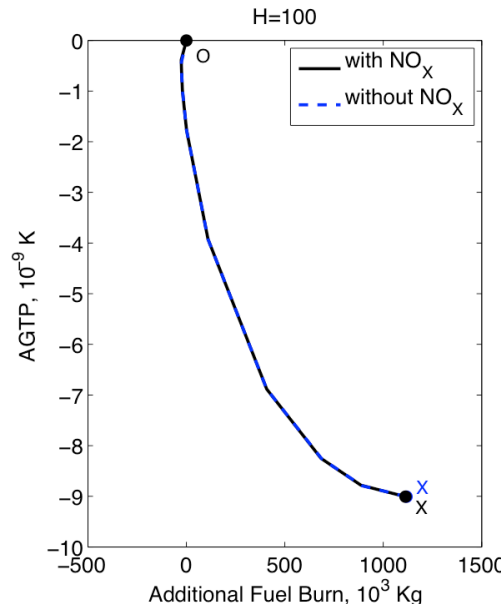

(a)

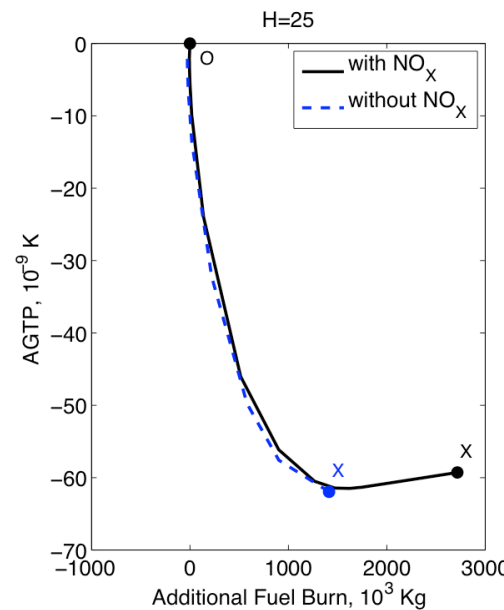

(b)

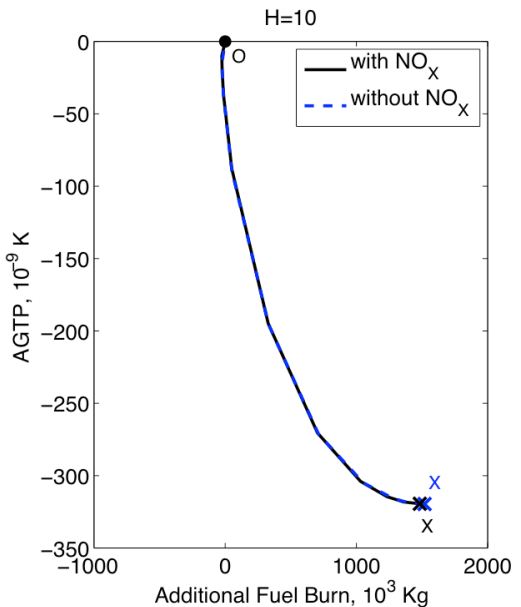

(c)

Figure 9. AGTP reduction $(\mathrm{H}=100,25,10$ years) versus additional fuel burn after the climate reduction strategy with and without considering $\mathrm{NO}_{\mathrm{X}}$ emissions for all flights on April 12, 2010.

\section{Conclusion}

This paper analyzes climate impact reduction strategies as equivalent to reducing the Absolute Global Temperature Potential due to aircraft emissions and contrails. The climate impact reduction strategy depends on the decision time horizon. The paper shows the trade-off between AGTP reduction and extra fuel consumption for the time horizons of 10, 25 and 100 years. An important contribution of the paper is the examination of the influence of NOx emissions on the climate reduction strategies. It is shown that for the 10 and 100 years time horizons, $\mathrm{NO}_{\mathrm{X}}$ emissions can be ignored in making the AGTP versus extra fuel trade-offs. In the intermediate decision horizon, around 25 years, the minimum climate impact point in the trade-off curve is slightly different with and without $\mathrm{NO}_{\mathrm{X}}$ emissions. The results presented in this study can be refined by considering the RF variations of contrails and $\mathrm{NO}_{\mathrm{X}}$ as a function of latitude, longitude, altitude and time. The results from this study can be used to make a preliminary selection of aviation emission operational strategies for a more detailed study or can be used as inputs to global climate modeling tools like the FAA's Aviation environmental Portfolio Management Tool for Impacts. 


\section{References}

${ }^{1}$ Duda, D.P., Minnis, P., Costulis, P.K., and Palikonda, R., "CONUS Contrail Frequency Estimated from RUC and Flight Track Data," European Conference on Aviation, Atmosphere, and Climate, Friedrichshafen at Lake Constance, Germany, JuneJuly 2003.

${ }^{2}$ Boucher, O., "Atmospheric science: Seeing through contrails," Nature Climate Change, 1, 24-25, 2011.

${ }^{3}$ Fuglestvedt, J. S., et al., "Transport impacts on Atmosphere and Climate: Metrics," Atmosphere Environment, Vol. 44, No. 37, 2010, pp. 4648-4677, doi: 10.1016/j.atmosenv.2009.04.044.

${ }^{4}$ Mannestein, H., and Schumann, U., “Aircraft Induced Contrail Cirrus over Europe,” Meteorol. Z. 14, pp. 549-554, 2005.

${ }^{5}$ Williams, V., and Noland, R. B., "Variability of contrail formation conditions and the implications for policies to reduce the climate impacts of aviation,"Transportation Research. Part D, Transport and environment, Vol. 10, No. 4, July 2005, pp. 269280 .

${ }^{6}$ Sridhar, B., Chen, N. Y., and Ng, H. K., "Energy Efficient Contrail Mitigation Strategies for Reducing the Environmental Impact of Aviation," Tenth USA/Europe Air Traffic Management Research and Development Seminar (ATM2013), Chicago, IL, June 2013.

${ }^{7}$ Köhler, M.O., Radel, G., Shine, K.P., Rogers, H.L., and Pyle, J.A., "Latitudinal variation of the effect of aviation NO emissions on atmospheric ozone and methane and related climate metrics," Atmosphere Environment, Vol. 64, 2013, pp. 1-9.

${ }^{8}$ http://www.faa.gov/about/office_org/headquarters_offices/apl/research/models/apmt/

${ }^{9}$ Köhler, M.O., Radel, G., Dessens, O., Shine, K.P., Rogers, H.L., Wild, O., Pyle, J.A., 2008. Impact of perturbations of nitrogen oxide emissions from global aviation. Journal of Geophysical Research 113, D11305

${ }^{10}$ Sridhar, B., Chen, N. Y., and Ng, H. K., "Integration of Linear Dynamic Emission and Climate Models with Air Traffic Simulations," AIAA Guidance, Navigation and Control Conference, Minneapolis, MN, 2012.

${ }^{11}$ Shine, K. P., Fuglestvedt, J. S., Hailemariam, K., Stuber, N., 2005b. "Alternatives to the global warming potential for comparing climate impacts of emissions of greenhouse gases," Climatic Change 68, 281-302.

${ }^{12}$ Forster, P., Ramaswamy, V., Artaxo, P., Berntsen, T., Betts, R., Fahey, D.W., Haywood, J., Lean, J., Lowe, D.C., Myhre, G., Nganga, J., Prinn, R., Raga, G., Schulz, M., Van Dorland, R., 2007a. Changes in atmospheric constituents and in radiative forcing. In: Solomon, S., et al. (Eds.), Climate Change 2007: the Physical Science Basis. Contribution of Working Group I to the Fourth Assessment Report of the Intergovernmental Panel on Climate Change. Cambridge University Press, Cambridge.

${ }^{13}$ Hartmann, D. L., Global Physical Climatology, Academic Press, San Diego, CA, 1994.

${ }^{14}$ Boucher, O., and Reddy, M. S., "Climate trade-off between black carbon and carbon dioxide emissions," Energy Policy, 36, pp 193-200, 2008.

${ }^{15}$ Fromming, C., et al., "Climate cost functions as a basis for climate optimized flight trajectories," Tenth USA/Europe Air Traffic Management Research and Development Seminar (ATM2013), Chicago, IL, June 2013.

${ }^{16}$ Meerkötter, R., Schumann, U., Minnis, P., Doelling, D. R., Nakajima, T., and Tsushima, Y. "Radiative Forcing by Contrails," Ann. Geophysicae, Vol. 17, 1999, pp. 1080-1094, doi: 10.1007/s00585-999-1080-7.

${ }^{17}$ Haywood, J. M., Allan, R. P., Bornemann, J., Forster, P. M., Francis, P. N., Milton, S., Rädel, G., Rap, A., Shine, K. P., and Thorpe, R., "A Case Study of the Radiative Forcing of Persistent Contrails Evolving into Contrail-Induced Cirrus," Journal of Geophysical Research, Vol. 114, D24201, doi:10.1029/2009JD012650, 2009.

${ }^{18}$ Schumann, U., Graf, K., and Mannstein, H., "Potential to Reduce the Climate Impact of Aviation by Flight Level Changes," 3rd AIAA Atmosphere Space Environments Conference, AIAA Paper 2011-3376, Honolulu, Hawaii, 2011.

${ }^{19}$ Sridhar, B., Chen, N. Y., and Ng, H. K.,. Sridhar, N. Chen, H. Ng and A. Morando, "Modeling and Simulation of the Impact of Air Traffic Operations on the Environment," Air Traffic Control Quarterly, Vol. 9, No. 1, 2001, pp. 1-20.

${ }^{20}$ Chen, N. Y., Sridhar, B., and Ng, H. K., "Tradeoff between Contrail Reduction and Emissions in United States National Airspace,” Journal of Aircraft, Vol. 49, No. 5, 2012, pp. 1367-1375. 